\title{
Loop Heat Pipe Operation with Thermoelectric Converters and Coupling Blocks
}

\author{
Jentung $\mathrm{Ku}^{1}$ \\ NASA Goddard Space Flight Center, Greenbelt, Maryland \\ Hosei Nagano ${ }^{2}$ \\ Japan Aerospace Exploration Agency, Kanagawa, Japan
}

\begin{abstract}
This paper presents theoretical and experimental studies on using thermoelectric converters (TECs) and coupling blocks to control the operating temperature of a miniature loop heat pipes (MLHP). The MLHP has two parallel evaporators and two parallel condensers, and each evaporator has its own integral compensation chamber (CC). A TEC is attached to each $\mathrm{CC}$, and connected to the evaporator via a copper thermal strap. The TEC can provide both heating and cooling to the $C C$, therefore extending the LHP operating temperature over a larger range of the evaporator heat load. A bi-polar power supply is used for the TEC operation. The bipolar power supply automatically changes the direction of the current to the $\mathrm{TEC}$, depending on whether the $\mathrm{CC}$ requires heating or cooling, to maintain the $C C$ temperature at the desired set point. The TEC can also enhance the startup success by maintaining a constant $\mathrm{CC}$ temperature during the start-up transient. Several aluminum coupling blocks are installed between the vapor line and liquid line. The coupling blocks serve as a heat exchanger which preheats the cold returning liquid so as to reduce the amount of liquid subcooling, and hence the power required to maintain the $\mathrm{CC}$ at the desired set point temperature. This paper focuses on the savings of the $\mathrm{CC}$ control heater power afforded by the TECs when compared to traditional electric heaters. Tests were conducted by varying the evaporator power, the condenser sink temperature, the $\mathrm{CC}$ set point temperature, the number of coupling blocks, and the thermal conductance of the thermal strap. Test results show that the TECs are able to control the $\mathrm{CC}$ temperature within $\pm 0.5 \mathrm{~K}$ under all test conditions, and the required TEC heater power is only a fraction of the required electric heater power.
\end{abstract}

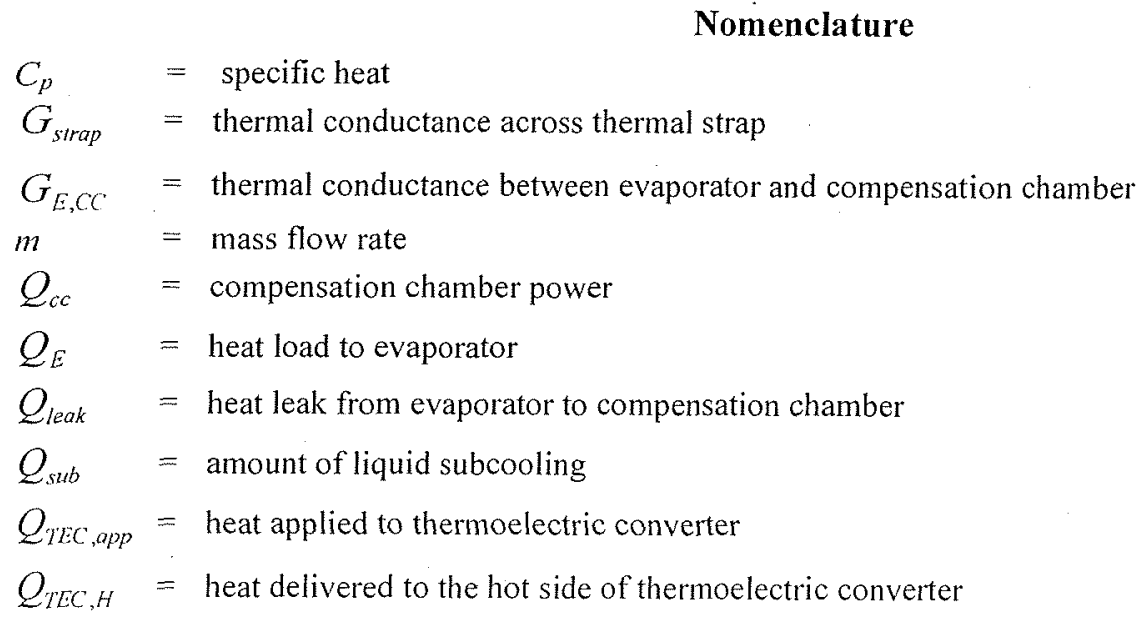

\footnotetext{
${ }^{1}$ Group Leader, Thermal Engineering Branch, Code 545, Goddard Space Flight Center, Greenbelt, Maryland, USA, AIAA Senior Member.

${ }^{2}$ NASA Visiting Researcher, Thermal Engineering Branch, Code 545, Greenbelt, Maryland 20771, AIAA Member.
} 


$$
\begin{array}{ll}
Q_{T E C, L} & =\text { heat absorbed by thermoelectric converter at the cold side } \\
T_{C C C} & =\text { temperature of compensation chamber } \\
T_{E} & =\text { temperature of evaporator } \\
T_{\text {in }} & =\text { temperature at the inlet of the compensation chamber } \\
T_{\min } & =\text { minimum temperature of the compensation chamber } \\
T_{S E T} & =\text { compensation chamber set point temperature } \\
T_{T E C, H} & =\text { temperature at the hot side of the thermoelectric converter } \\
T_{T E C, L} & =\text { temperature at the cold side of thermoelectric converter } \\
\lambda & =\text { latent heat of vaporization }
\end{array}
$$

\section{Introduction}

LOOP heat pipe (LHP) is a very robust and versatile thermal device which can transport large heat loads over A long distance with small temperature differences, ${ }^{1,2}$. LHPs are being used on several commercial communications satellites and NASA's ICESAT, SWIFT, AURA, and GOES-N spacecraft ${ }^{3-7}$. It continues to gain increasing acceptance as a heat transfer device for spacecraft and instrument thermal control.

The LHP operating temperature is governed by the saturation temperature of its compensation chamber $(\mathrm{CC})$; the latter is in turn determined by the balance among the heat leak from the evaporator to the $\mathrm{CC}$, the amount of subcooling carried by the liquid returning to the $C C$, and the amount of heat exchanged between the $C C$ and ambient. For a well-insulated CC, the heat leak is balanced by the liquid subcooling as shown in Figure 1. Thus,

$$
\begin{aligned}
& Q_{\text {leak }}-Q_{\text {sub }}=0 \\
& Q_{\text {leak }}=G_{E, C C}\left(T_{E}-T_{C C}\right) \\
& Q_{\text {sub }}=m C_{p}\left(T_{C C}-T_{i n}\right) \\
& m=Q_{E} / \lambda
\end{aligned}
$$

The heat leak is usually a few percentage of the heat load applied to the evaporator. The amount of subcooling is a function of the condenser sink temperature, ambient temperature and evaporator heat load. When the ambient temperature is higher than the condenser sink temperature, the $\mathrm{CC}$ temperature as a function of the evaporator heat load yields a V-shaped curve as shown in Fig. 2. This can be explained as follows. At a low heat load, the liquid flow rate along the liquid line is small, resulting in a long residence time there. The liquid will be heated to near the ambient temperature due to a parasitic heat gain from ambient. Thus, the $\mathrm{CC}$ temperature will rise above the ambient temperature in order to satisfy the energy balance requirement. As the evaporator heat load increases, the mass flow rate increases and the residence time of the returning liquid in the liquid line decreases. This leads to a lower liquid temperature at the $\mathrm{CC}$ inlet and an increasing amount of liquid subcooling. The increase in the liquid subcooling more than compensates for the increase in the heat leak, leading to a decrease of the $\mathrm{CC}$ temperature. This trend continues until the condenser is fully utilized and the $\mathrm{CC}$ temperature reaches a minimum ( $\mathrm{T}_{\text {nin }}$ in Fig. 2). Any increase in the evaporator heat load thereafter will result in warm liquid flowing back to the $\mathrm{CC}$. The $\mathrm{CC}$ temperature will increase in order for the condenser to be able to dissipate the heat load.

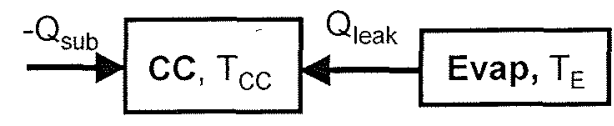

Figure 1. Energy Balance for $\mathrm{CC}$

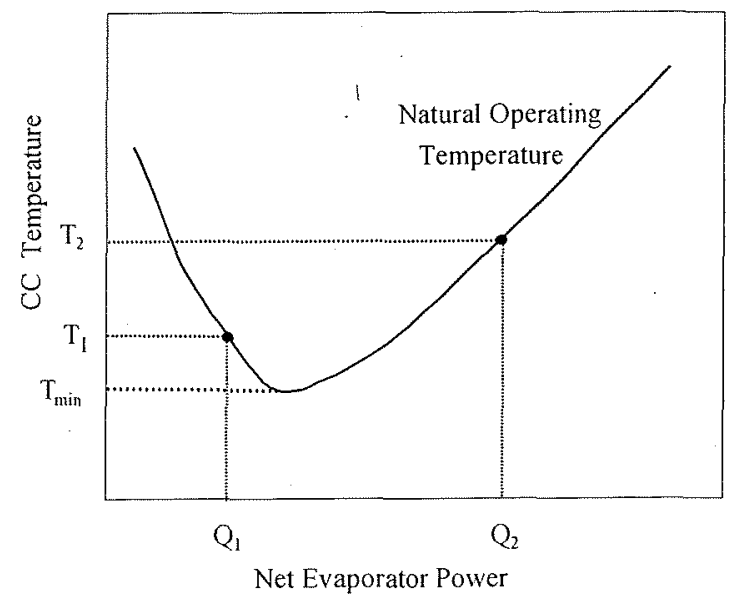

Figure 2. LHP Natural Operating Temperature 
Most spacecraft applications require the instrument temperature to be kept within a narrow range. The LHP operating temperature can be controlled at a fixed set point required by the instrument (e.g. $T_{\text {SET }}$ as shown in Fig. 3) by adding heat to or removing heat from the CC. As shown in Fig. 4, the energy balance becomes:

$$
Q_{\text {leak }}-Q_{\text {sub }}+Q_{C \mathrm{C}}=0
$$

Thus,

$$
Q_{c C}=Q_{s u b}-Q_{\text {leak }}
$$

A positive $\mathrm{Qcc}_{\mathrm{cc}}$ denotes the heat to be added to the $\mathrm{CC}$ whereas a negative $\mathrm{Q}_{c c}$ denotes the heat to be removed. In Fig. 3, $Q_{C C}$ is positive for evaporator heat loads between $Q_{\text {Low }}$ and $Q_{\text {High. }}$ For evaporator heat load smaller than $\mathrm{Q}_{\text {Low }}, \mathrm{Q}_{\mathrm{CC}}$ is negative and the $\mathrm{CC}$ requires cooling. Note that when the heat load is greater than $Q_{\text {Hight }}$, the condenser is fully utilized at $\mathrm{T}_{\mathrm{SET}}$ and the only way to maintain the $\mathrm{CC}$ temperature at $\mathrm{T}_{\mathrm{SET}}$ is to increase the condenser heat dissipating capacity, i.e. increase the radiator size.

Saturation temperature control is accomplished traditionally by cold-biasing the CC and using an electric heater to maintain the set point temperature. This method can only provide heating to the $\mathrm{CC}$, i.e. the set point temperature can only be maintained for the evaporator heat load between $Q_{\text {Low }}$ and $Q_{\text {High, }}$ as illustrated in Fig. 3. Moreover, the required CC control heater power can be as high as 30 percent of the evaporator heat load when the condenser sink is very cold.

Several methods have been used to reduce the control heater power requirement. The first method uses coupling blocks that are installed between the vapor line and liquid line $e^{3,4}$. The cold liquid returning to the $\mathrm{CC}$ will acquire heat from the vapor and thus become less subcooled when entering the $\mathrm{CC}$. The second method

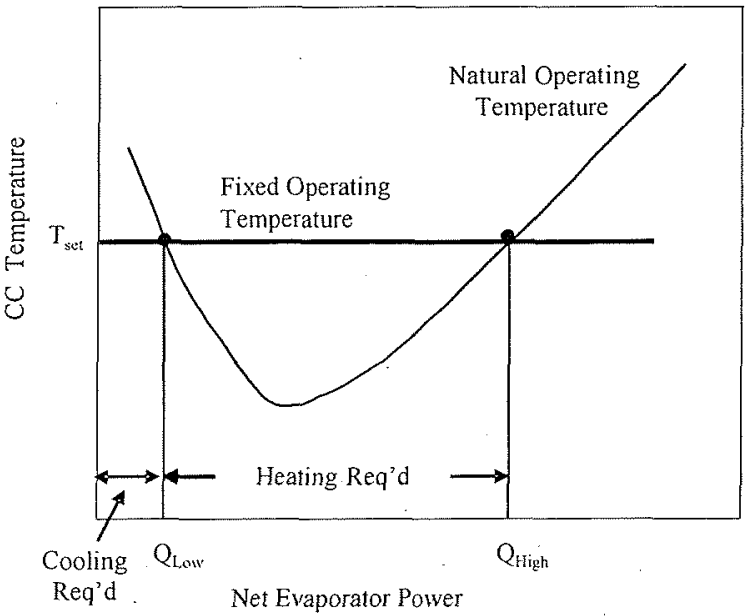

Figure 3. LHP Operating Temperature Control

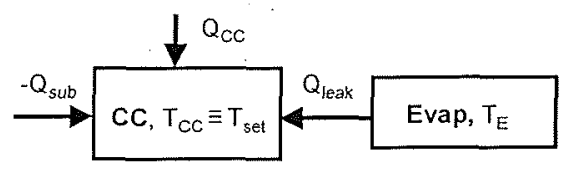

Figure 4. Energy Balance for $\mathrm{CC}$ uses a pressure regulating valve to divert part of the vapor from the vapor line to the liquid line, thereby reducing the liquid subcooling. A feedback mechanism is required for implementing this method. The third method uses a variable conductance heat pipe that connects the evaporator and the liquid line $\mathrm{e}^{5-7}$. A feedback mechanism is also required for the implementation of such a method. Some of these methods have certain disadvantages: 1) Liquid subcooling could be further reduced at low evaporator powers, leading to an even higher natural operating temperature; 2) Liquid subcooling could also be reduced during the loop start-up with low evaporator powers precisely when high subcooling is critically needed; and 3) There could be a significant delay in the response of the feedback mechanism.

This paper describes theoretical and experimental studies to investigate the use of a thermoelectric converter (TEC) and coupling blocks to control the CC saturation temperature of an LHP. A TEC is capable of providing both heating and cooling to the $\mathrm{CC}$. Thus, using a single device, the $\mathrm{CC}$ temperature can be maintained at $\mathrm{T}_{\mathrm{SET}}$ for evaporator heat loads from 0 to $\mathrm{Q}_{\mathrm{High}}$. (shown in Fig. 3). When heating the $\mathrm{CC}$, a TEC can also reduce the required control heater power when compared to using electric heaters. The test article used for this investigation is a miniature LHP (MLHP) consisting of two evaporators and two condensers. Each evaporator has its own integral CC, and a TEC is installed on each CC.

The remainder of the paper is arranged as follows. A theoretical background of $\mathrm{CC}$ temperature control using TEC is given first. This is followed by descriptions of the test article and test set-up. Details of the tests performed and test results are then presented. Effects of the thermal conductance of the thermal strap and the number of coupling blocks on the required TEC power are also addressed. 


\section{Theoretical Background}

A TEC operates based on the Peltier effect, which states that when an electric current flows through two dissimilar conductors, the junction of the two conductors will either absorb or release heat depending on the direction of the current flow. Details of the operating principles, construction, and performance characteristics of TECs can be found in the literature and on TEC vendors' web sites $^{9-12}$. The amount of heat that a TEC can pump is a function of its design, the power that drives the TEC, the temperature of the TEC hot side, and the temperature difference between its TEC hot and cold sides. There are different ways to present the performance characteristics of a TEC. One of the methods is depicted in Figure 5 where performance curves of the Marlow Industries DT3-6 $\mathrm{TEC}^{10}$ at a hot side temperature of $300 \mathrm{~K}$ are shown. For example, when a voltage of 1 volt is applied to the TEC, an electric current between 1.1 and 1.7 amps will flow to the TEC. The exact current is a function of the heat being pumped. If the current is $1.5 \mathrm{amps}$ (the applied power is $1.5 \mathrm{~W}$ ) and the temperature difference across the TEC is $20 \mathrm{~K}$, then the heat being pumped (the "HEAT LOAD" on the chart) is about $2 \mathrm{~W}$. When the direction of the current is reversed, the hot side and the cold side of the TEC will switch, and the direction of the heat flow will also reverse. In other words, the TEC switches it mode of operation from heating to cooling an objective, or vice versa. This is why a single TEC can be used to heat or cool the same object. Note that the hot side of the TEC must be connected to a heat sink for ultimate heat dissipation. Otherwise, the hot side will get hotter and hotter. When the temperature difference between the hot side and the cold side exceeds a certain value, the TEC will cease to pump heat. This is shown in Fig. 5 as the $0 \mathrm{~W}$ heat load line.

Hot Side Temperature: $27^{\circ} \mathrm{C}$

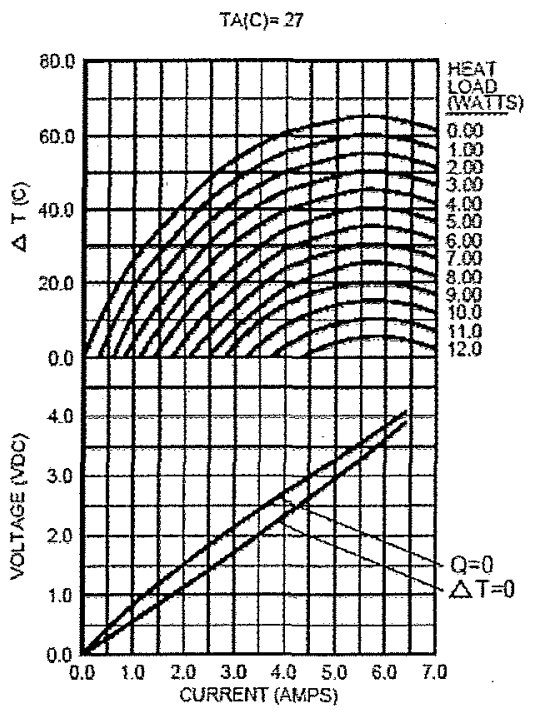

Figure 5. Performance Curves for Marlow Industries DT3-6 TEC at 300K Hot Side Temperature ${ }^{8}$

When a TEC is used to control the CC set point temperature in an LHP, one side of the TEC can be attached to a copper saddle which is attached to the $\mathrm{CC}$, and the other side can be connected to the evaporator via a copper strap as shown in Figure 6. By changing the direction of the current flowing through the TEC, the TEC will change its mode of operation from heating the $\mathrm{CC}$ to cooling the $\mathrm{CC}$. Using a bipolar power supply and a control algorithm, the TEC will automatically change its mode of operation to maintain the $\mathrm{CC}$ at the desired set point temperature. When a power is applied to the TEC, the TEC will pump heat from the cold side to the heat side. The sum of the applied power and heat being pumped is delivered to the hot side of the TEC. Thus,

$$
Q_{T E C, H}=Q_{T E C, L}+Q_{T E C, a p p}
$$

When the TEC is heating the CC as shown in Fig. 6, part of the heat applied to the evaporator will be transmitted to the cold side of the TEC via the thermal strap. This heat plus the heat applied to the TEC is used to heat to CC. Figure 7 shows the heat flow. Thus,

$$
Q_{C C}=Q_{T E C, H}
$$

$\mathrm{Q}_{C C}$ is the required power to maintain the $\mathrm{CC}$ at the set point temperature. From Equation (7), one can write:

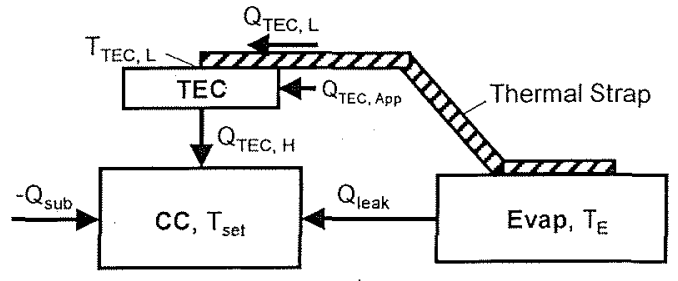

Figure 6. Schematic of TEC Heating CC

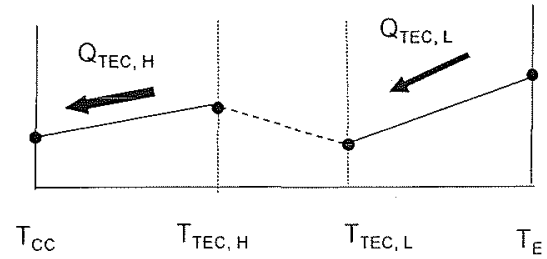

Figure 7 Heat Flow with TEC Heating CC 


$$
Q_{T E C, a p p} \leq Q_{C C}
$$

Using traditional electric heaters, the required control power is Qcc. Using a TEC, the required control power is $\mathrm{Q}_{\mathrm{TEC}, \text { app }}$. The TEC can therefore reduce the control heater power requirement for the CC. The power saving is $\mathrm{Q}_{\mathrm{TEC}, \mathrm{L}}$, which is the same as the heat being transmitted from the evaporator to the $\mathrm{CC}$ through the thermal strap, i.e.

$$
Q_{T E C, L}=Q_{\text {Strap }}=G_{\text {strap }}\left(T_{E}-T_{T E C, L}\right)
$$

When the TEC is cooling the CC as is shown in Fig. 8, the power applied to the TEC plus the heat that is absorbed from the $\mathrm{CC}$ is delivered to the hot side of the TEC. The heat is then transferred via the thermal strap to the evaporator, and is ultimately dissipated to the condensers. Figure 9 shows the heat flow. In addition to Eq. (7), one can write the following equations:

$$
\begin{aligned}
& Q_{C C}=Q_{T E C, L} \\
& Q_{T E C, H}=Q_{\text {Strap }}=G_{\text {srrap }}\left(T_{T E C, H}-T_{E}\right)
\end{aligned}
$$

When the TEC is heating the $\mathrm{CC}$, its hot side is at nearly the same temperature as the $\mathrm{CC}$. The cold side will become cold and reach an equilibrium temperature, $\mathrm{T}_{\mathrm{TEC}, \mathrm{L}}$, which simultaneously satisfies the following conditions: 1) The TEC will pump a heat load of $\mathrm{Q}_{\text {load }}$ which is determined from Fig. 5 based on the voltage applied to the TEC and the temperature difference across the TEC. 2) $Q_{\text {load }}$ is equal to $Q_{T E C, L}$, the heat transmitted from the

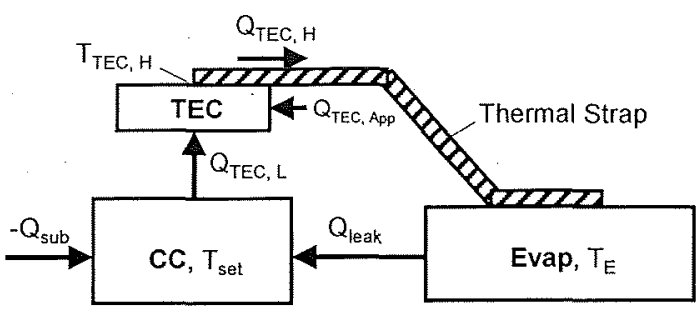

Figure 8. Schematic of TEC Cooling CC

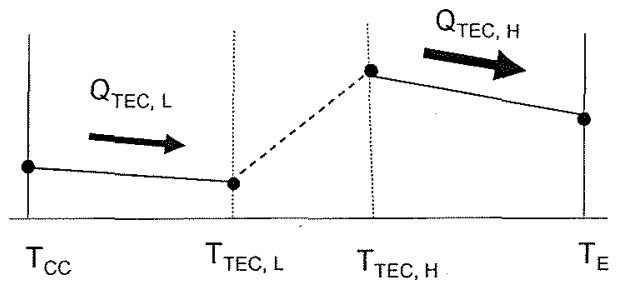

Figure 9. Heat Flow with TEC Cooling CC evaporator through the thermal strap. 3) Because $\mathrm{Q}_{\mathrm{TEC}, \mathrm{L}}$ is transmitted from the evaporator through the thermal strap, Eq. (10) must be satisfied.

When the TEC is cooling the CC, the TEC cold side will be at a temperature slightly lower than the CC set point temperature. The hot side will reach an equilibrium temperature, $T_{\mathrm{TEC}, \mathrm{H}}$, which simultaneously satisfies the following conditions: 1) The TEC will pump a heat load of $\mathrm{Q}_{\text {load, }}$ which is determined from Fig. 5 based on the voltage applied to the TEC and the temperature difference across the TEC. Qload is the same as $Q_{T E C, L}$. 2) A heat load of $\mathrm{Q}_{\mathrm{TEC}, \mathrm{H}}$ is delivered to the hot side of the TEC. $\mathrm{Q}_{\mathrm{TEC}, \mathrm{H}}$ is the sum of $\mathrm{Q}_{\mathrm{TEC}, \mathrm{L}}$ and the power applied to the TEC, i.e. Eq. (7) must be satisfied. 3) Because $\mathrm{Q}_{\mathrm{TEC}, \mathrm{H}}$ is transmitted to the evaporator through the thermal strap, Eq. (12) must be satisfied.

It is obvious that cooling the $\mathrm{CC}$ requires more heat to be transmitted through the thermal strap than heating the CC when the same power is applied to the TEC. Thus, the TEC efficiency is more strongly affected by the thermal conductance of the strap when it cools the $\mathrm{CC}$ than when it hearts the CC. Moreover, because the evaporator is already at a higher temperature than the $\mathrm{CC}$, the temperature of the TEC hot side must be higher than the evaporator temperature. The smaller the strap thermal conductance, the warmer the TEC hot side will become. Because the cold side is more or less constant (near the CC temperature), a warmer hot side increases the temperature difference across the TEC, and makes the TEC work less efficiently. More power must be applied to the TEC in order to pump the same amount of heat out of the CC. More power to the TEC makes the hot side even warmer and further reduces the TEC efficiency. Thus, a vicious cycle may develop and eventually lead to a total loss of the TEC pumping capability, i.e. the TEC will operate along the zero heat load line on the chart shown in Fig. 5. When that happens, the TEC cannot cool the CC.

On the other hand, when the TEC is heating the $\mathrm{CC}$, the hot side is at nearly the same temperature as the CC. Because the evaporator is already at a slightly higher temperature than the $\mathrm{CC}$, and the TEC cold side is colder than the $\mathrm{CC}$, some heat will definitely be transmitted from the evaporator through the thermal strap to the cold side of the TEC. The higher the thermal conductance of the thermal strap is, the more heat is transmitted. Even if no heat is being transmitted across the strap, using a TEC is no worse than using an electric heater. 
The coupling blocks connecting the vapor line and liquid line serve as a heat exchanger which heats the cold liquid as it flows back to the evaporator and $\mathrm{CC}$. This will reduce the liquid subcooling, which in turn will reduce the control heater power required to maintain the $\mathrm{CC}$ at the desired set point temperature (refer to Eqs. (3) and (6)). In addition, the natural operating temperature curve shown in Fig. 2 is a function of the condenser sink temperature. As the sink temperature decreases, the natural operating temperature curve moves lower except at very low evaporator heat loads. Thus, the heater power increases with a decreasing sink temperature.

One possible disadvantage of using coupling blocks may occur during low power operation and low power startup. At low evaporator powers, the $\mathrm{CC}$ temperature may be higher than the ambient temperature. When coupling blocks are added, the operating temperature will become even higher because the liquid subcooling is further reduced. If a thermal mass is attached to the evaporator and the loop is started with a low power, the loop may not reach a steady temperature. This is because the returning liquid does not provide enough subcooling to balance the heat leak. As the CC temperature increases, the net heat to the evaporator decreases because the thermal mass utilizes part of the heat load to raise its own temperature. A decreasing evaporator heat load leads to an even higher $\mathrm{CC}$ temperature (refer to. Fig. 2). Thus, the loop temperature may continue to increase and exceed the maximum allowable temperature of the instrument. By cooling the $\mathrm{CC}$ to keep the saturation temperature constant, the TEC solves both the start-up and low power operation problems. Moreover, the power required to operate the TEC is very small at low evaporator powers.

\section{Test Article and Test Set-up}

Figure 10 shows a picture of the MLHP, which consisted of two parallel evaporators, two parallel condensers, a common vapor transport line and a common liquid return line. Major design parameters of the MLHP are summarized in Table 1. An aluminum block with a 400-gram mass was attached to each evaporator to simulate the instrument. The two parallel condensers were sandwiched between two aluminum plates. A flow regulator consisting of capillary wicks was installed at the downstream of the two condensers. In addition, the vapor line and

Table 1. Summary of MLHP Design Parameters

\begin{tabular}{|c|c|c|}
\hline Component & Material & Value \\
\hline $\begin{array}{l}\text { Evaporators } \\
(2)\end{array}$ & $\begin{array}{l}\text { Aluminum } \\
6061\end{array}$ & $9 \mathrm{~mm}$ O.D. $\times 52 \mathrm{~mm} \mathrm{~L}$ \\
\hline $\begin{array}{l}\text { Primary } \\
\text { Wicks }(2)\end{array}$ & Titanium & $\begin{array}{l}6.35 \mathrm{~mm} \text { O.D. } \times 3.2 \mathrm{~mm} \text { I.D } \\
\text { Porosity: } 0.35 \\
\text { Pore radius } 1.39 \mu \mathrm{m}(\mathrm{E} 1) \text {, } \\
1.47 \mu \mathrm{m}(\mathrm{E} 2) \\
\text { Permeability: } 0.11 \times 10^{-13} \mathrm{~m}^{2} \\
(\mathrm{E} 1), 0.09 \times 10^{-13} \mathrm{~m}^{2}(\mathrm{E} 2)\end{array}$ \\
\hline $\begin{array}{l}\text { Secondary } \\
\text { Wicks (2) }\end{array}$ & $\begin{array}{l}\text { Stainless } \\
\text { Steel }\end{array}$ & $\begin{array}{l}\text { Porosity: } 0.67 \\
\text { Pore radius: } 68.7 \mu \mathrm{m} \\
\text { Permeability: } 83 \times 10^{-13} \mathrm{~m}^{2} \\
\end{array}$ \\
\hline $\begin{array}{l}\text { Bayonet } \\
\text { Tubes (2) }\end{array}$ & SS 304L & $1.1 \mathrm{~mm}$ O.D. $x 0.79 \mathrm{~mm}$ I.D. \\
\hline $\mathrm{CC}(2)$ & SS 304L & $\begin{array}{l}22.2 \mathrm{~mm} \mathrm{O.D.} \times 21.2 \mathrm{~mm} \mathrm{I.D.} \\
\times 72.4 \mathrm{~mm} \mathrm{~L}\end{array}$ \\
\hline Vapor Line & SS 304L & $\begin{array}{l}2.38 \mathrm{~mm} \text { O.D. x } 1.37 \mathrm{~mm} \mathrm{I.D.} \\
\times 914 \mathrm{~mm} \mathrm{~L}\end{array}$ \\
\hline Liquid Line & SS 304L & $\begin{array}{l}1.59 \mathrm{~mm} \mathrm{O.D.} \times 1.08 \mathrm{~mm} \text { I.D. } \\
\times 914 \mathrm{~mm} \mathrm{~L}\end{array}$ \\
\hline $\begin{array}{l}\text { Condensers } \\
\text { (2) }\end{array}$ & SS 304L & $\begin{array}{l}2.38 \mathrm{~mm} \text { O.D. } \times 1.37 \mathrm{~mm} \text { I.D. } \\
\times 2540 \mathrm{~mm} \mathrm{~L}\end{array}$ \\
\hline $\begin{array}{l}\text { Flow } \\
\text { Regulator }\end{array}$ & SS & $\begin{array}{l}\text { Pore radius: } 10.1 \mu \mathrm{m} \\
\text { Permeability: } 3.1 \times 10^{-13} \mathrm{~m}^{2}\end{array}$ \\
\hline $\begin{array}{l}\text { Working } \\
\text { fluid }\end{array}$ & Ammonia & 29.3 grams \\
\hline $\begin{array}{l}\text { Total LHP } \\
\text { mass }\end{array}$ & & 316.6 grams \\
\hline
\end{tabular}

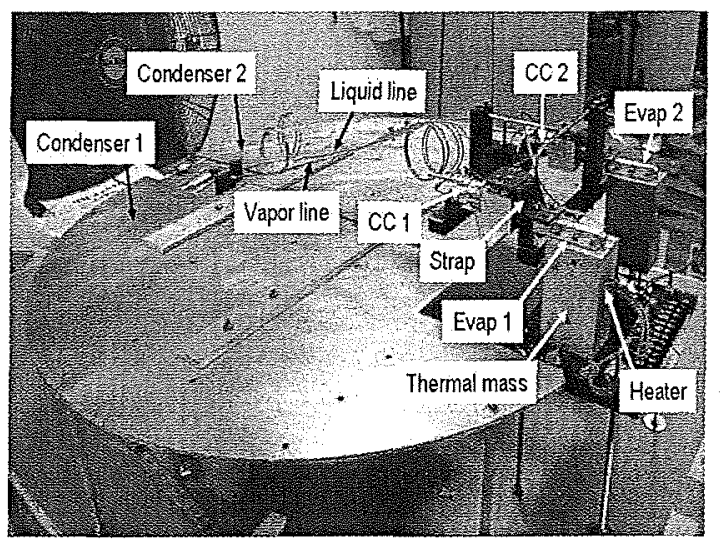

Figure 10. Picture of the MLHP

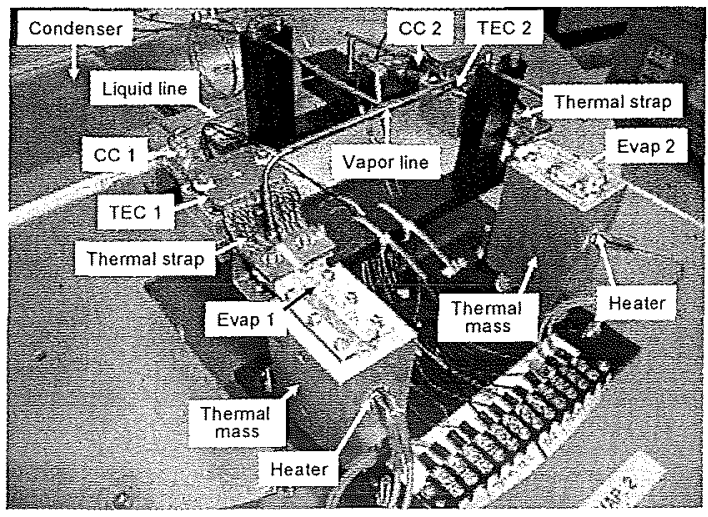

Figure 11. Close-up View of the Evaporator and $/ \mathrm{CC}$

6

American Institute of Aeronautics and Astronautics 
liquid line were connected with several aluminum coupling blocks $(20 \mathrm{~mm}$ by $20 \mathrm{~mm}$ by $6 \mathrm{~mm}$ each) to reduce the control heater power for the CCs. A TEC made by Marlow Industries with model number DT3-6 was installed on each $C C$ through an aluminum saddle ${ }^{10}$. The other side of the TEC was connected to the evaporator through a copper strap. A close-up view of the evaporator/CC section showing the TECs and thermal straps is depicted in Fig. 11.

A cartridge heater capable of delivering $1 \mathrm{~W}$ to $200 \mathrm{~W}$ was inserted into each thermal mass. The applied power was obtrained from the multiplication of the measured voltage and current. Each condenser cold plate was cooled convectively by a separate chiller. The two chillers allowed temperatures of the two condenser plates to vary independently. Each TEC was controlled by a bi-polar power supply. Changing the polarity of the applied voltage changed the direction of the current flow, and the mode of the TEC operation from heating the CC to cooling the CC. The entire test set-up was placed in a horizontal plane.

To investigate the effect of the thermal conductance of the strap on the TEC operation, two typess of copper thermal strap designs were used in the test as shown in in Fig. 11 and Fig. 12, respecively. The first type of strap has a thermal conductance of $0.22 \mathrm{~W} / \mathrm{K}$, and the second $0.5 \mathrm{~W} / \mathrm{K}$. These thermal conductance values were obtained from thermal vacuum testing of both types of staraps. Two straps of each type were used, one for each CC/evaporator pair. In addition, various numbers of coupling blocks were used: $0,2,3$ and 4 blocks.

More than 60 type $\mathrm{T}$ thermocouples were used to monitor the MLHP temperatures, as shown in Figure 14. A data acquisition system consisting of a data logger, a personal computer, and a screen monitor was used to collect and store temperature and power data every second. Labview software was used for the command and control of the test conditions.

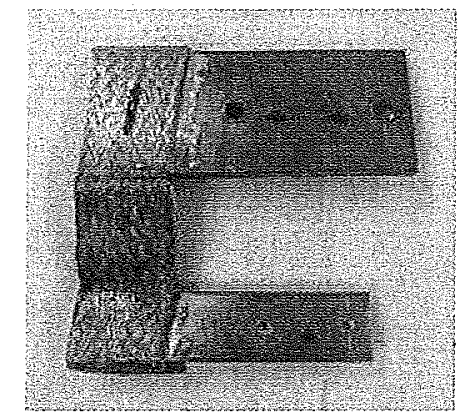

Figure 12. Type 1 Thermal Strap

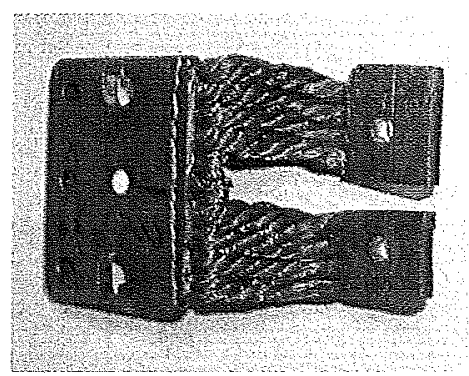

Figure 13. Type 2 Thermal Strap

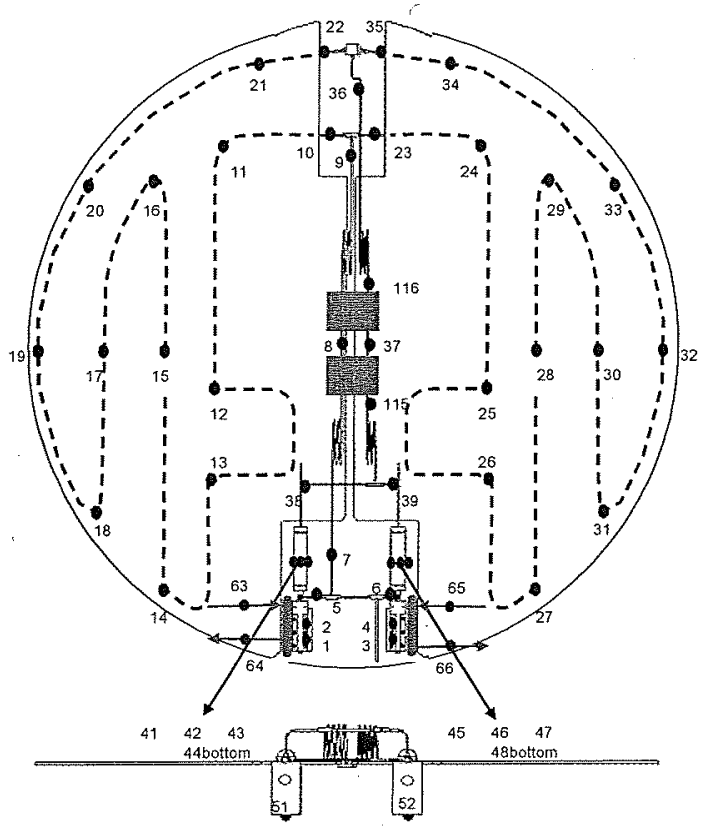

Figure 14. Thermocouple Locations (Top View)

\section{Tests Performed and Experimental Results}

The TEC installed on the CC serves three purposes: 1) to provide active cooling to the $\mathrm{CC}$ to maintain the $\mathrm{CC}$ set point temperature; 2) to replace traditional electric heaters to heat the $\mathrm{CC}$ and maintain the $\mathrm{CC}$ set point temperature; and 3 ) to reduce the control heater power when heating the CC. Figure 15 shows the test where TECs were used to cool the CCs. Type 2 thermal straps were used and no coupling block was attached. The condenser 1 and condenser 2 (C1/C2) sinks were kept at $273 \mathrm{~K} / 273 \mathrm{~K}$, and the ambient temperature was $295 \mathrm{~K}$. With a heat load of $5 \mathrm{~W} / 5 \mathrm{~W}$ to evaporator 1 and evaporator 2 (E1/E2), the loop natural operating temperature rose above $297 \mathrm{~K}$. The loop operating temperature was stable at $296 \mathrm{~K}$ when the E1/E2 heat load was increased to $10 \mathrm{~W} / 10 \mathrm{~W}$. When both CCs were controlled by TECs, the operating temperature was kept at $290 \mathrm{~K}$, below the ambient temperature, at heat loads of 
$10 \mathrm{~W} / 10 \mathrm{~W}$ and $5 \mathrm{~W} / 5 \mathrm{~W}$. The required TEC power was less than $3 \mathrm{~W}$ during the transient and only a small fraction of $1 \mathrm{~W}$ during the steady state operation. The loop would not be able to operate at $290 \mathrm{~K}$ if electric heaters alone were used to maintain the $\mathrm{CC}$ temperatures.

Figure 16 shows the loop temperatures in a test where the heat load to E1/E2 varied between $75 \mathrm{~W} / 0 \mathrm{~W}$ and $0 \mathrm{~W} / 75 \mathrm{~W}$ while the $\mathrm{Cl}$ sink temperature was kept at $273 \mathrm{~K}$ and $\mathrm{C} 2$ sink temperature varied between $263 \mathrm{~K}$ and $293 \mathrm{~K}$. Type 2 thermal straps were used and no coupling block was attached. The TECs were able to control the loop operating temperature at $303 \mathrm{~K}$ at all times regardless of whether $\mathrm{CC} 1, \mathrm{CC} 2$, or both were being controlled at the set point temperature, and regardless of changes of the evaporator heat load distribution and the condenser sink temperature. The TEC power needed to maintain each $\mathrm{CC}$ temperature was no more than $3 \mathrm{~W}$, which was typical for all tests.

Extensive tests were conducted on the MLHP to verify the TEC temperature control function in the laboratory and thermal vacuum environments ${ }^{13-15}$. This paper focuses on the power savings realized by using TECs when compared to using electric heaters. Tests were also conducted to investigate the effects of thermal strap conductance and the number of coupling blocks on the control heater power requirements. Tests were conducted by varying the evaporator power and the condenser sink temperature. Table 2 presents the entire test matrix.

There were nine test groups, and each group comprised two tests. In the first test, both $\mathrm{CC} 1$ and $\mathrm{CC} 2$ were maintained at $303 \mathrm{~K}$, and both $\mathrm{C} 1$ and $\mathrm{C} 2$ sinks were kept

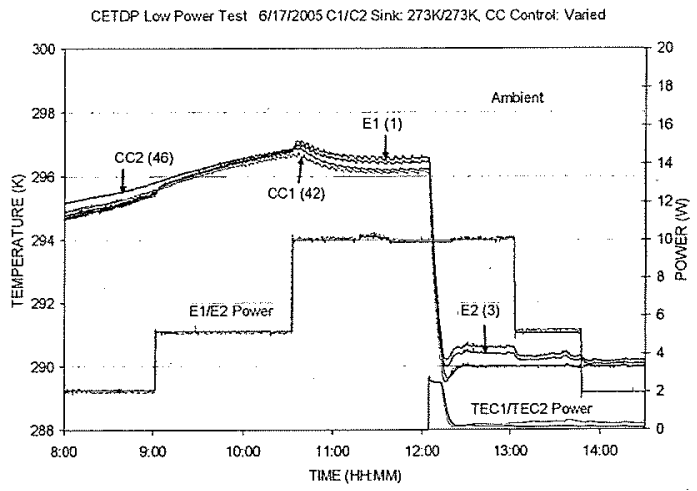

Figure 15. Temperature Profiles in a Low Power Test

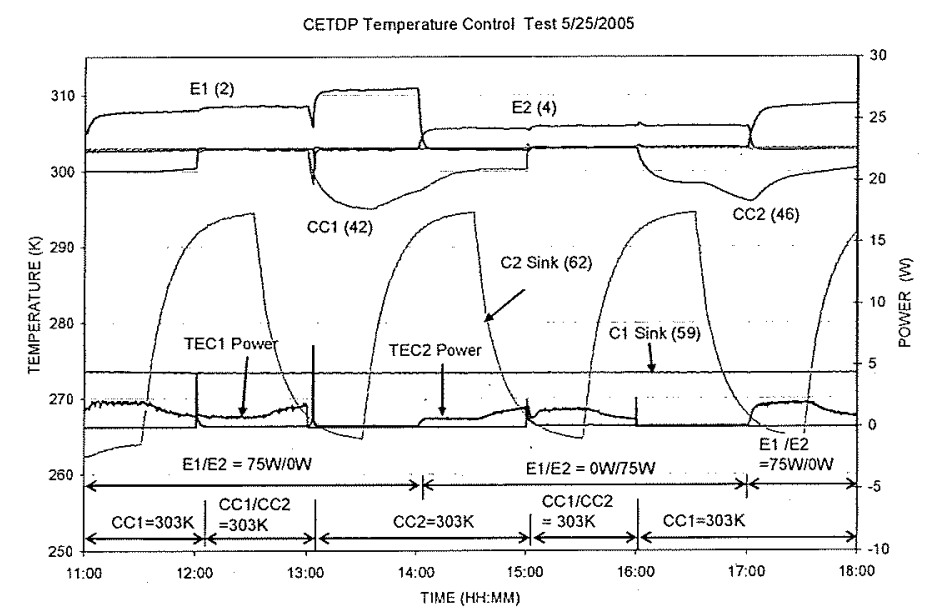

Figure 16. Saturation Temperature Control Using TECs at $273 \mathrm{~K}$. In the second test, both $\mathrm{CC1}$ and $\mathrm{CC} 2$ were maintained at $313 \mathrm{~K}$, and both $\mathrm{Cl}$ and $\mathrm{C} 2$ sinks were maintained at $253 \mathrm{~K}$. When an electric heater (EH) was used to heat the $\mathrm{CC}$, the applied voltage was continuously adjusted until the $\mathrm{CC}$ temperatures was within $\pm 0.5 \mathrm{~K}$ of the set point temperature and the heater was no longer cycling on and off. The electric heater power was obtained by multiplying the measured voltage by the measured current. When a TEC was used, the applied voltage was automatically adjusted by the control algorithm using a proportional/integrator scheme. In most case, a steady state was reached within 10 minutes although the test continued for 30 minutes at each power level. The power consumed by the TEC was calculated by multiplying the measured voltage by the measured current. The TEC power had a low voltage and a high current. Therefore, the voltage was measured directly across the TEC so as to exclude the voltage drop along the wires between the power supply and the TEC. This was important because the line voltage drop was typically larger than that across the TEC itself. It should be noted the relationship between the measured current and the measured voltages across the TEC matched those shown in Figure 5.

The power saving of using a TEC to heat the CC as compared to using an electric heater will be discussed first. Unless specifically stated, type 2 thermal straps were used in all tests. Figure 17 shows the results when both CCs were maintained at $303 \mathrm{~K}$ and both condenser sinks were kept at $273 \mathrm{~K}$. There was no coupling block between the vapor line and the liquid line. Using an electric heater to heat $\mathrm{CCl}$, the required heater power ranged from $1.5 \mathrm{~W}$ at an evaporator heat load of $20 \mathrm{~W}$ to $2.5 \mathrm{~W}$ at an evaporator heat load of $70 \mathrm{~W}$. By comparison, using TEC1 to heat 
$\mathrm{CCl}$, the required TEC1 power was less than $0.4 \mathrm{~W}$ for all heat loads. Similar results were obtained when using TEC2 to heat $\mathrm{CC} 2$. Thus, the required $\mathrm{TEC}$ power was less than 20 percent of the electric heater power. The power savings was derived from the heat transmitted from the evaporator to the $\mathrm{CC}$ through the thermal strap. The amount of heat transmitted through the thermal strap was calculated from Eq. 10 using the strap thermal conductance and the temperature difference across the strap at each evaporator heat load, and is shown in Fig. 17 in pink colors. This value agreed very well with the measured power savings, which was the difference between the electric heater power and the power applied to the TEC.

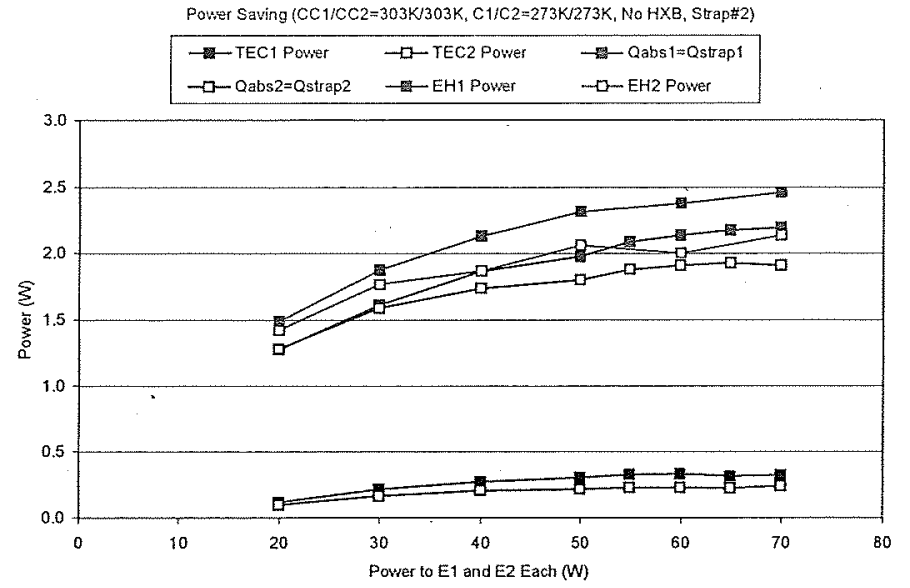

Figure 17. Power Required to Control CC Saturation Temperature at $303 \mathrm{~K}$

Table 2. Summary of Tests Performed

\begin{tabular}{|c|c|c|c|c|c|c|}
\hline $\begin{array}{l}\text { Test } \\
\text { Group }\end{array}$ & $\begin{array}{l}\text { Strap } \\
\text { Used }\end{array}$ & $\begin{array}{l}\text { Heating } \\
\text { Method }\end{array}$ & $\begin{array}{l}\text { No. of } \\
\text { Blocks }\end{array}$ & $\begin{array}{l}\text { CC } 1 / \mathrm{CC} 2 \\
\text { Temp }(\mathrm{K})\end{array}$ & $\begin{array}{c}\text { C1/C2 } \\
\text { Sink } \\
\text { Temp (K) }\end{array}$ & $\begin{array}{l}\text { Power Applied to E1/E2 } \\
\qquad(W)\end{array}$ \\
\hline \multirow[b]{2}{*}{1} & \multirow[b]{2}{*}{1} & \multirow[b]{2}{*}{ TEC } & \multirow[b]{2}{*}{2} & $303 / 303$ & $273 / 273$ & $20 / 20,30 / 30,40 / 40,50 / 50,55 / 55,60 / 60,65 / 65,70 / 70$ \\
\hline & & & & $313 / 313$ & $253 / 253$ & $\begin{array}{l}10 / 10,20 / 20,30 / 30,40 / 40,50 / 50,60 / 60,65 / 65,70 / 70 \\
75 / 75,80 / 80\end{array}$ \\
\hline \multirow{2}{*}{2} & \multirow{2}{*}{1} & \multirow{2}{*}{ TEC } & \multirow{2}{*}{0} & $303 / 303$ & $273 / 273$ & $\begin{array}{l}10 / 10,20 / 20,30 / 30,40 / 40,50 / 50,55 / 55,60 / 60,65 / 65 \\
70 / 70,75 / 75,80 / 80\end{array}$ \\
\hline & & & & $313 / 313$ & $253 / 253$ & $\begin{array}{l}10 / 10,20 / 20,30 / 30,40 / 40,50 / 50,60 / 60,65 / 65,70 / 70 \\
75 / 75,80 / 80\end{array}$ \\
\hline \multirow[b]{2}{*}{3} & \multirow[b]{2}{*}{1} & \multirow[b]{2}{*}{$\mathrm{EH}$} & \multirow[b]{2}{*}{0} & $303 / 303$ & $273 / 273$ & $20 / 20,30 / 30,40 / 40,50 / 50,60 / 60,70 / 70,75 / 75,80 / 80$ \\
\hline & & & & $313 / 313$ & $253 / 253$ & $\begin{array}{l}10 / 10,20 / 20,30 / 30,40 / 40,50 / 50 \text { (insufficient heater } \\
\text { power) }\end{array}$ \\
\hline \multirow[b]{2}{*}{4} & \multirow[b]{2}{*}{2} & \multirow[b]{2}{*}{ TEC } & \multirow[b]{2}{*}{2} & $303 / 303$ & $273 / 273$ & $20 / 20,30 / 30,40 / 40,50 / 50,55 / 55,60 / 60,65 / 65,70 / 70$ \\
\hline & & & & $313 / 313$ & $253 / 253$ & $\begin{array}{l}10 / 10,20 / 20,30 / 30,40 / 40,50 / 50,60 / 60,70 / 70,75 / 75 \\
80 / 80\end{array}$ \\
\hline \multirow[b]{2}{*}{5} & \multirow[b]{2}{*}{2} & \multirow[b]{2}{*}{$\mathrm{TEC}$} & \multirow[b]{2}{*}{0} & $303 / 303$ & $273 / 273$ & $20 / 20,30 / 30,40 / 40,50 / 50,55 / 55,60 / 60,65 / 65,70 / 70$ \\
\hline & & & & $313 / 313$ & $253 / 253$ & $\begin{array}{l}10 / 10,20 / 20,30 / 30,40 / 40,50 / 50,60 / 60,70 / 70,75 / 75 \\
80 / 80\end{array}$ \\
\hline \multirow[b]{2}{*}{6} & \multirow[b]{2}{*}{2} & \multirow[b]{2}{*}{$\mathrm{EH}$} & \multirow[b]{2}{*}{0} & $303 / 303$ & $273 / 273$ & $20 / 20,30 / 30,40 / 40,50 / 50,55 / 55,60 / 60,65 / 65,70 / 70$ \\
\hline & & & & $313 / 313$ & $253 / 253$ & $\begin{array}{l}10 / 10,20 / 20,30 / 30,40 / 40,50 / 50,60 / 60,70 / 70,75 / 75 \\
80 / 80\end{array}$ \\
\hline \multirow[b]{2}{*}{7} & \multirow[b]{2}{*}{2} & \multirow[b]{2}{*}{ EH } & \multirow[b]{2}{*}{2} & $303 / 303$ & $273 / 273$ & $20 / 20,30 / 30,40 / 40,50 / 50,55 / 55,60 / 60,65 / 65,70 / 70$ \\
\hline & & & & $313 / 313$ & $253 / 253$ & $\begin{array}{l}10 / 10,20 / 20,30 / 30,40 / 40,50 / 50,60 / 60,70 / 70,75 / 75 \\
80 / 80\end{array}$ \\
\hline \multirow[b]{2}{*}{8} & \multirow[b]{2}{*}{2} & \multirow[b]{2}{*}{ TEC } & \multirow[b]{2}{*}{3} & $303 / 303$ & $273 / 273$ & $20 / 20,30 / 30,40 / 40,50 / 50,55 / 55,60 / 60,65 / 65,70 / 70$ \\
\hline & & & & $313 / 313$ & $253 / 253$ & $\begin{array}{l}10 / 10,20 / 20,30 / 30,40 / 40,50 / 50,60 / 60,70 / 70,75 / 75 \\
80 / 80\end{array}$ \\
\hline \multirow[b]{2}{*}{9} & \multirow[b]{2}{*}{2} & \multirow[b]{2}{*}{ TEC } & \multirow[b]{2}{*}{4} & $303 / 303$ & $273 / 273$ & $20 / 20,30 / 30,40 / 40,50 / 50,55 / 55,60 / 60,65 / 65,70 / 70$ \\
\hline & & & & $313 / 313$ & $253 / 253$ & $\begin{array}{l}10 / 10,20 / 20,30 / 30,40 / 40,50 / 50,60 / 60,70 / 70,75 / 75 \\
80 / 80\end{array}$ \\
\hline
\end{tabular}


Figure 18 shows the results when tests were conducted under the same conditions except that both CCs were kept at $313 \mathrm{~K}$ and both condenser sinks at $253 \mathrm{~K}$. As the difference between the CC set point temperature and the condenser sink temperature increased, the liquid subcooling also increased. Thus, the required electric heater power and the TEC power both increased. Test results show that, the required TEC power was less than 35 percent of the required electric heater power. Moreover, the heat transmitted from the evaporator to the CC through the thermal strap agreed very well with the measured power savings. Tests were then conducted by installing two aluminum blocks connecting the vapor and liquid lines.

Figure 19 shows the power required to maintain the CCs at $303 \mathrm{~K}$ when the condenser sinks were kept constant at $273 \mathrm{~K}$. When only electric heaters were used to heat the $\mathrm{CCs}$, adding two coupling blocks on the transport lines reduced the required electric heater power by 30 to 40 percent. Similar savings on the required TEC power was obtained by adding two coupling blocks on the transport lines when TECs were used to heat the CCs. Figure 20 shows the results on tests where both CCs were maintained at $313 \mathrm{~K}$ and both condenser sinks at 253K. Again, adding two coupling blocks saved the required electric heater power by up to 40 percent, and the required TEC power by up to 50 percent. Both figures show that using TECs could save much more electric heater power than adding two coupling blocks.

Although it is true that adding more coupling blocks would reduced the liquid subcooling and the required electric heater power to maintain the desired $\mathrm{CC}$ temperatures, such an action could have undesirable effects on the LHP operation at low evaporators powers and during the start-up transient unless TECs were also used. No test was conducted by adding more than two coupling blocks when electric heaters were used to heat the CCs. However, tests were performed to evaluate the effect of adding two, three and four coupling blocks when TECs were used to heat the CCs. The results are shown in Figures 21 and 22 .

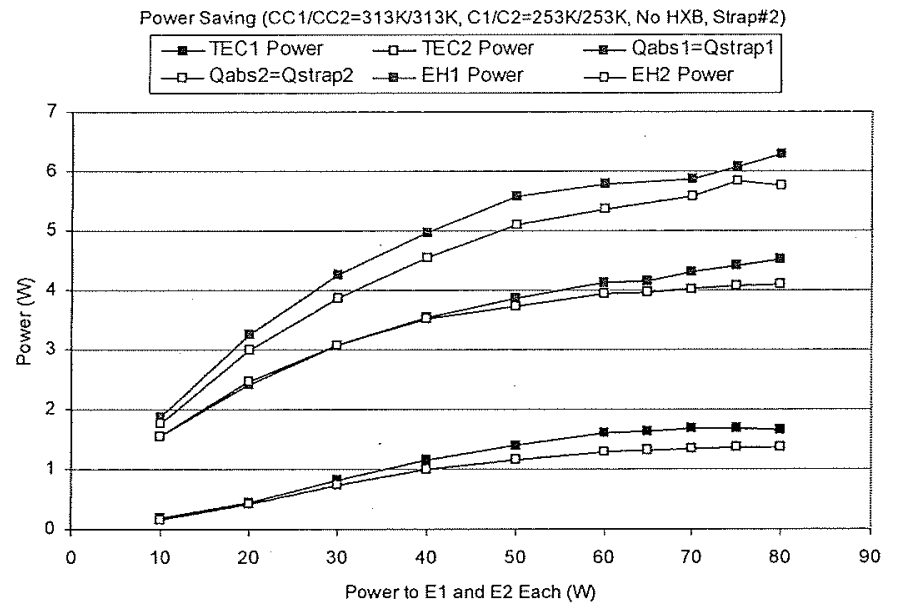

Figure 18. Power Required to Control CC Saturation Temperature at $313 \mathrm{~K}$

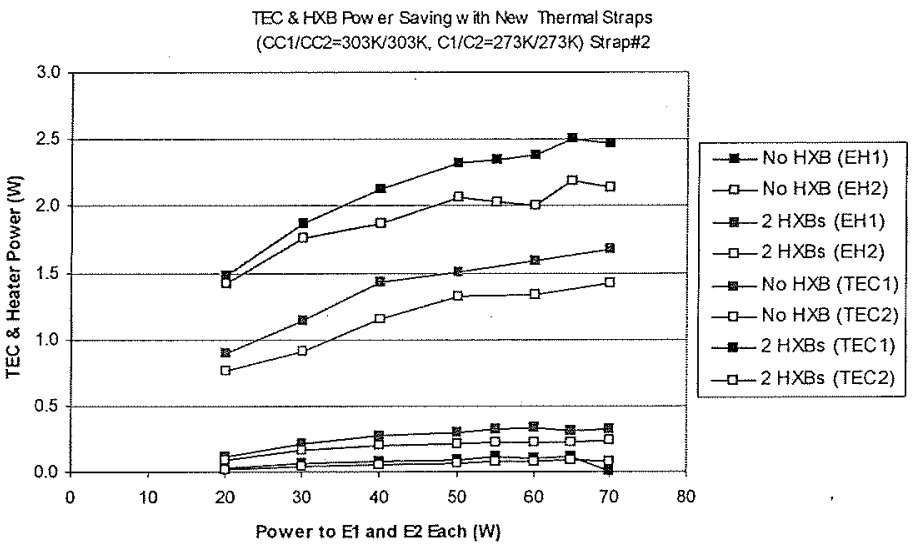

Figure 19. Power Required to Control CC Saturation Temperature at $303 \mathrm{~K}$

Although adding two coupling blocks reduced the required $\mathrm{TEC}$ power significantly when compared to no coupling block as discussed earlier, adding more than two coupling locks did not appear to have any effect on the required TEC power. In fact, the test data scattered, possibly due to uncertainties in measurements of the voltage and current across the TECs at such low values.

Tests were also conducted by using Type 1 thermal straps to study the effect of strap thermal conductance on the required TEC power. Figure 23 shows the results when both $\mathrm{CCs}$ were kept at $303 \mathrm{~K}$ and both condenser sinks were kept at $273 \mathrm{~K}$, while Figure 24 shows the results when both CCs were kept at $313 \mathrm{~K}$ and both condenser sinks were kept at $253 \mathrm{~K}$. A higher strap thermal conductance allowed heat to be transmitted more easily from the evaporator to the TEC cold side, and made the TEC work more efficiently. Consequently, the required TEC power reduced. 


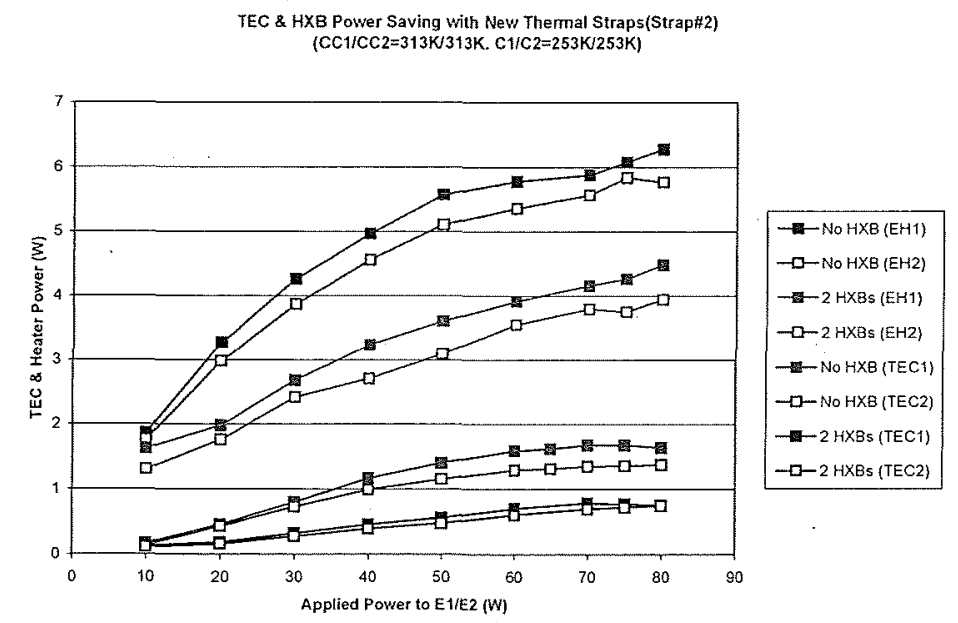

Figure 20 Power Required to Control CC Saturation Temperature at 313K

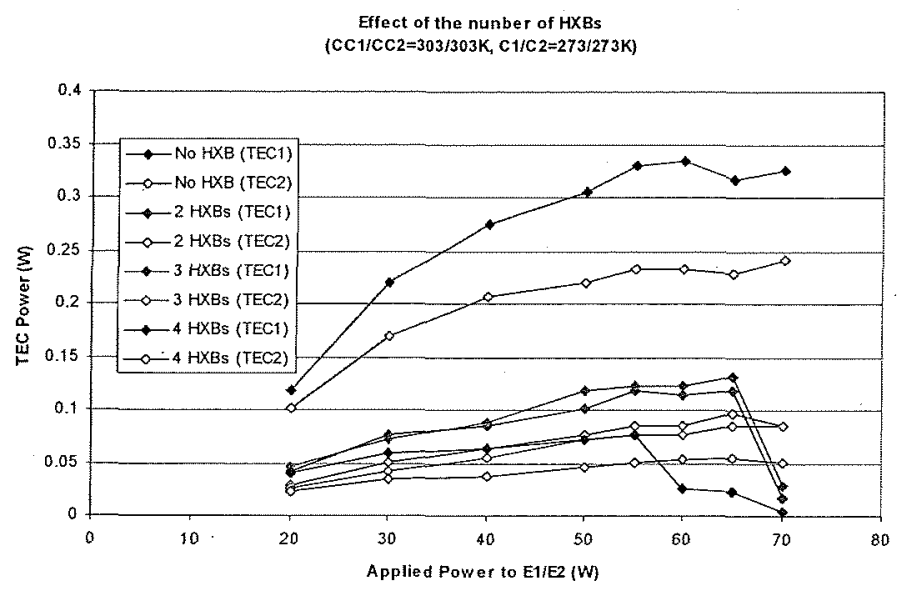

Figure 21. Required TEC Power as a Function of Number of Coupling Blocks 


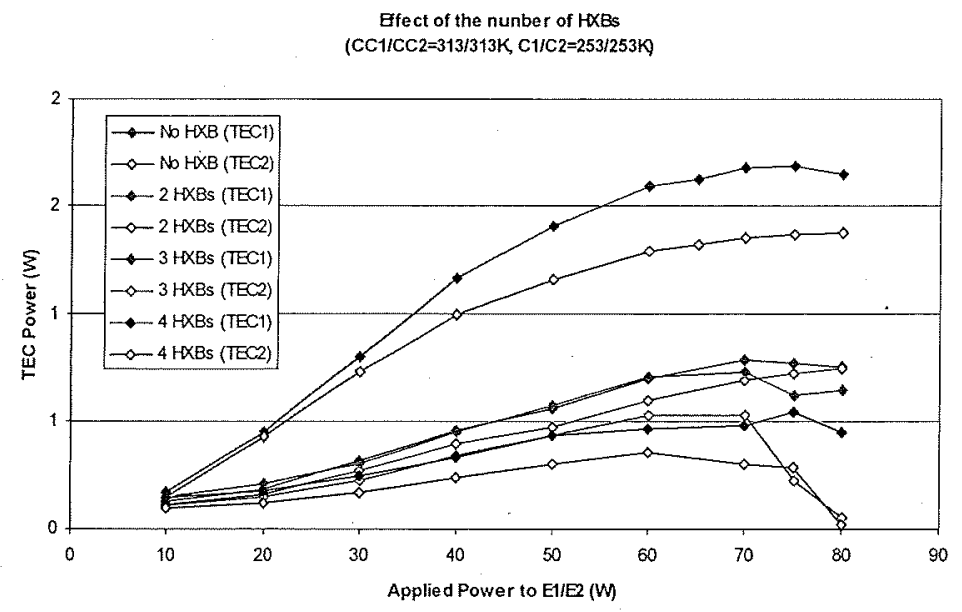

Figure 22. Required TEC Power as a Function of Number of Coupling Blocks

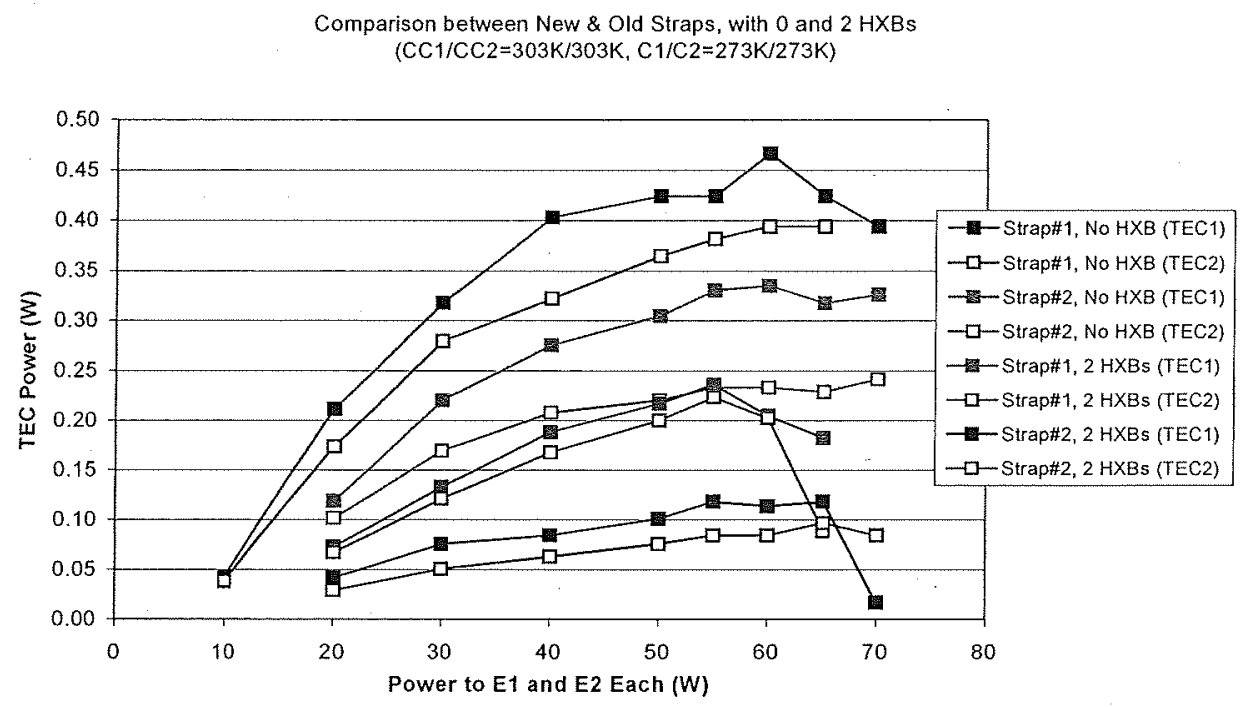

Figure 23. Required TEC power Using Different Thermal Straps 


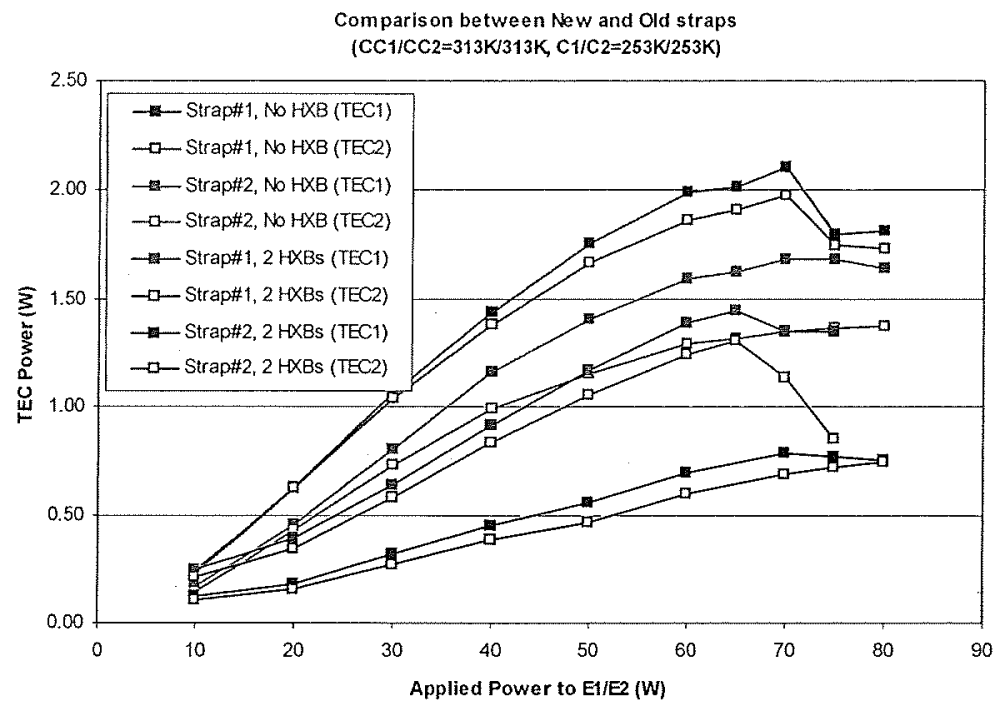

Figure 24. Required TEC power Using Different Thermal Straps

\section{Conclusion}

This study investigated the use of TECs and coupling blocks to control the saturation temperature of the CCs in a miniature LHP with two evaporators and two condensers. Experimental results show that TECs were able to control the LHP operating temperature within $\pm 0.5 \mathrm{~K}$ of the desired set point temperature regardless of changes in the evaporator heat load and/or the condenser sink temperature. The TECs could provide both heating and cooling to the CCs as opposed to heating only when traditional methods were used. Moreover, using a bipolar power supply, the TEC could automatically switch from heating to cooling to control the CC temperature. When heating the CCs, the required TEC power was significantly less than the required electric heater power.

The coupling blocks pre-heated the cold liquid returning to the $\mathrm{CC}$, thus reducing the liquid subcooling and the required control heat power regardless of whether TECs or electric heaters were used. The combination of TECs and coupling blocks could provide an optimal means to control the $\mathrm{CC}$ saturation temperature while augmenting the range of the evaporator power under which the $\mathrm{CC}$ temperature could be controlled. The ability of the TEC to cool the CC should also enhance the success of the LHP start-up with low evaporator heat loads.

\section{References}

1. Maidanik, Y., and Fershtater, Y., "Theoretical Basis and Classification of Loop Heat Pipes and Capillary Pumped Loops," $10^{\prime h}$ International Heat Pipe Conference, Stuttgart, Germany, 1997.

2. Ku, J., "Operating Characteristics of Loop Heat Pipes," SAE Paper No. 1999-01-2007, 29 International Conference on Environnental Systems, Society of Automotive Engineers, Denver, Colorado, July I2-15, 1999.

3. Baker, C., Butler, D., Ku, J., and Grob, E., "Acceptance Thermal Vacuum Tests of the GLAS Flight Loop Heat Pipe Systems," Space Technology and Applications International Forum-2001, Albuquerque, New Mexico, February 11-14, 2001.

4. Baker, C and Grob, E." "System Accommodation of Propylene Loop Heat Pipes for The Geoscience Laser Altimeter System (GLAS) Instrument," SAE Paper No. 2001-01-2263, 31" International Conference on Environmental Systems, Society of Automotive Engineers, Orlando, Florida, July 9-12, 2001.

5. Ottenstein, L., Ku, J., and Feenan, D., "Thermal Vacuum Testing of a Novel Loop Heat Pipe Design for the Swift BAT Instrument," Space Technology and Applications International Forum -2003, Albuquerque, New Mexico, February 2-6, 2003.

6. Choi, M., "Thermal Vacuum/Balance Test Results of Swift BAT with Loop Heat Pipe Thermal System", AIAA Paper No. 20045683, $2^{\text {nd }}$ Intersociety Energy Conversion Engineering Conference (IECEC), Providence, Rhode Island, August 16-19, 2004.

7. Choi, M., "Thermal Assessment of Swift BAT Instrument Thermal Control System In Flight", SAE Paper No. 2005-01-3037, 35 International Conference on Environmental Systems, July 11-14, 2005, Rome, Italy. 
8. Gancharov, K., "Development of Loop Heat Pipe with Pressure Regulator," SAE Paper No. 2006-01-2171, 36"it International Conference on Environmental Systems, Society of Automotive Engineers, Norfolk, Virginia, July 17 20, 2006.

9. Rowe, D. M. (ed.), CRC Handbook of Thermoelectrics CRC Press, New York, 1995.

10. Marlow Industries' web site, URL: http://www.marlow.com

11. Melcor Corporation's web site, URL: http://www.melcor.com

12. Tellurex Corporation's web site, URL: http://www.tellurex.com

13. Nagano, $\mathrm{H}$. and $\mathrm{Ku}, \mathrm{J}$., "Gravity Effect on Capillary Limit of a Miniature Loop Heat Pipe with Multiple Evaporators and Multiple Condensers," Space Technology and Applications International Forum -2007, Albuquerque, New Mexico, February 11-15, 2007.

14. Ku, J., Ottenstein, L., Butler, D. and Nagano, H., "Thermal Performance of a Miniature Loop Heat Pipe with Multiple Evaporators and Multiple Condensers," I $4^{\text {th }}$ International Heat Pipe Conference, Florianópolis, Brazil, April 22-27, 2007.

15. Ku, J. and Nagano, H., "Effects of Gravity on Start-up and Heat Load Sharing of a Miniature Loop Heat Pipe," SAE Paper No. 2007-01-3234, 37 th International Conference on Environnental Systems, Chicago, Illinois, July 9-12, 2007.

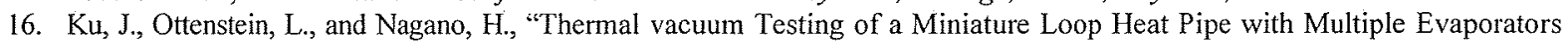
and Multiple Condensers," Paper No. HT2007-32302, ASME Summer Heat Transfer Conference, July 8-12, 2007, Vancouver, British Columbia, Canada. 